\title{
Identification of TRPC6 as a possible candidate target gene within an amplicon at 11q21-q22.2 for migratory capacity in head and neck squamous cell carcinomas
}

Sandra Bernaldo de Quirós ${ }^{1}$, Anna Merlo', Pablo Secades', Iriana Zambrano', Ines Saenz de Santa María', Nerea Ugidos', Eloisa Jantus-Lewintre ${ }^{2}$, Rafael Sirera ${ }^{3}$, Carlos Suarez ${ }^{1}$ and María-Dolores Chiara ${ }^{1 *}$

\begin{abstract}
Background: Cytogenetic and gene expression analyses in head and neck squamous cell carcinomas (HNSCC) have allowed identification of genomic aberrations that may contribute to cancer pathophysiology. Nevertheless, the molecular consequences of numerous genetic alterations still remain unclear.

Methods: To identify novel genes implicated in HNSCC pathogenesis, we analyzed the genomic alterations present in five HNSCC-derived cell lines by array CGH, and compared high level focal gene amplifications with gene expression levels to identify genes whose expression is directly impacted by these genetic events. Next, we knocked down TRPC6, one of the most highly amplified and over-expressed genes, to characterize the biological roles of TRPC6 in carcinogenesis. Finally, real time PCR was performed to determine TRPC6 gene dosage and mRNA levels in normal mucosa and human HNSCC tissues.

Results: The data showed that the HNSCC-derived cell lines carry most of the recurrent genomic abnormalities previously described in primary tumors. High-level genomic amplifications were found at four chromosomal sites (11q21-q22.2, 18p11.31-p11.21, 19p13.2-p13.13, and 21q11) with associated gene expression changes in selective candidate genes suggesting that they may play an important role in the malignant behavior of HNSCC. One of the most dramatic alterations of gene transcription involved the TRPC6 gene (located at 11q21-q22.2) which has been recently implicated in tumour invasiveness. siRNA-induced knockdown of TRPC6 expression in HNSCC-derived cells dramatically inhibited HNSCC-cell invasion but did not significantly alter cell proliferation. Importantly, amplification and concomitant overexpression of TRPC6 was also found in HNSCC tumour samples.
\end{abstract}

Conclusions: Altogether, these data show that TRPC6 is likely to be a target for 11q21-22.2 amplification that confers enhanced invasive behavior to HNSCC cells. Therefore, TRPC6 may be a promising therapeutic target in the treatment of HNSCC.

Keywords: Head and neck squamous cell carcinoma, TRPC6, Invasion, Gene amplification

\footnotetext{
* Correspondence: mdchiara.uo@uniovi.es

'Servicio de Otorrinolaringología, Hospital Universitario Central de Asturias, Instituto Universitario de Oncología del Principado de Asturias, Universidad de Oviedo, Oviedo, Spain

Full list of author information is available at the end of the article
} 


\section{Background}

The broad application of cytogenetic and molecular genetics methods has led to the identification of tumorassociated chromosomal regions substantial for the tumorigenesis and progression of head and neck squamous cell carcinomas (HNSCC) [1-3]. Comprehensive analysis of recurrent amplified chromosomal regions has allowed identification of oncogenes and other cancerrelated gene such as EMS1, CCND1, PPFIA1, TAOS1 (11q13), LOXL4 (10q24), PAK4 (19q13), and HIF1A (14q23-q24) which have been associated with different clinical behaviors [4-10]. Therefore, associations of high-level genomic amplifications with altered gene expression and functional analysis of the affected genes represents an excellent approach to identify novel genes involved in tumor progression and carcinogenesis.

Here, we compared the genome-wide DNA copy number alterations present in five HNSCC-derived cell lines with those previously reported in tumour tissues. Remarkably, our data showed that the cell lines analyzed here resemble most of the important genomic alterations previously described in primary HNSCC. It also revealed the presence of several regions with high level focal amplifications (11q21-22.2, 18p11.31-p11.21, 19p13.2-p13.13, and 21q11) that have been previously identified in HNSCC $[1,11]$.

Although rarely detected in solid tumors, high level amplification at 11q22-q23 has been described not only in HNSCC $[12,13]$ but in many malignancies including glioblastomas, renal cell carcinomas, sarcomas, and cervical, lung and pancreatic cancers [14-19] thus suggesting that this region may harbor gene(s) that, when amplified, have an active role in tumorigenesis and/or cancer progression. YAP gene has been identified as a candidate target gene in 11q22 amplicon in several human cancers [20-22]. However, to date, no specific genes have been proposed as targets in HNSCC.

In the present report, we performed gene expression analysis of the amplified genes in each amplicon identified in HNSCC-derived cell lines what allowed the identification of 12 novel genes with potential implications in HNSCC biology. One of the most dramatically amplified and overexpressed gene identified here is TRPC6, a member of the transient receptor potential (TRPC) subfamily, located at 11q22.1. This novel genetic change was also identified in primary HNSCC-tumour samples. Remarkably, recent studies have revealed that TRPC6 has an essential role in glioma growth, invasion, and angiogenesis $[23,24]$. We show here that TRPC6 overexpression confers enhanced invasive behavior to HNSCC cells. Therefore, TRPC6 may have an essential role in the development of the aggressive phenotype of HNSCC and may be a promising therapeutic target in the treatment of HNSCC.

\section{Methods}

\section{Cell lines}

The five established human HNSCC cell lines used in this study were kindly provided by Dr. Grenman [25]. Cell lines were derived from primary tumors located at the oral cavity (SCC2 and SCC40 cell lines) and larynx (SCC29, SCC38 and SCC42B cell lines). Cells were grown in Dulbecco's modified Eagle's medium supplemented with $10 \%$ fetal bovine serum, 100 units $/ \mathrm{ml}$ penicillin, $200 \mu \mathrm{g} / \mathrm{ml}$ streptomycin, $2 \mathrm{mM}$ L-glutamine, $20 \mathrm{mM}$ Hepes $\mathrm{pH} 7.3$ and $100 \mu \mathrm{M}$ non-essential aminoacids. All cells were maintained at $37^{\circ} \mathrm{C}$ in $5 \% \mathrm{CO}_{2}$.

\section{Tissue samples}

Surgical tissue specimens from 24 patients with HNSCC were obtained, following institutional review board guidelines, from the Hospital Universitario Central de Asturias and Hospital General Universitario de Valencia. All the procedures utilized in this study are in agreement with the 1975 Helsinki Declaration. Informed consent was obtained from each patient. All the patients included in our study underwent surgical resection of their tumor and bilateral neck dissection (functional or radical based on surgical findings). All of them had a single primary tumor; none had undergone treatment prior to surgery, and had microscopically clear surgical margins. A portion of the surgical tissue specimen was sharply excised, placed in sterile tubes, and stored at $-80^{\circ} \mathrm{C}$ in RNAlater (Ambion) for DNA and RNA analysis. Clinically normal adjacent mucosa and normal mucosa from non-cancer patients were also collected. All patients were habitual tobacco and alcohol consumers.

\section{DNA and RNA isolation}

Genomic DNA was isolated using the QIAmp DNA Mini kit (Qiagen, Inc., Chatsworth, CA) and subsequently treated with RNase A (1unit $/ \mathrm{mL}$ ) at $37^{\circ} \mathrm{C}$ for 5 minutes. Total RNA was isolated from HNSCC cell lines and tumour tissues with Nucleospin RNA II (Macherey-Nagel, Easton, PA) following the manufacturer's instructions with the addition of an extra acid phenol/chloroform extraction followed by RNA precipitation.

\section{Array-CGH}

Arrays-CGH were performed as described by van den Ijssel et al. [26]. Briefly, tumour cell lines and reference DNAs (pooled from 10 different donors) were differently labelled by random priming. Three hundred ng test and reference DNA were hybridized to an array containing approximately 30,000 DNA oligos spread across the whole genome printed on Codelink activated slides (Amersham Biosciences, Barcelona, Spain). This array contained 29,134 oligos covering 28,830 unique genes. Hybridization and washing took place for two nights in a 
specialized hybridization chamber (GeneTAC/HybArray12 hybstation; Genomic Solutions/Perkin Elmer). Images were acquired using a Microarray Scanner G2505B (Agilent Technologies). Analysis and data extraction were quantified by BlueFuse (BlueGnome, Cambridge, UK). Gains were defined as at least two neighbouring oligonucleotides with deviations of 0.2 or more from $\log 2$ ratio $=0.0$. High-level amplification was considered when at least two neighbouring clones reached a log2 ratio of 1.0 or higher.

\section{qPCR}

Real-time PCR was done in an ABI Prism 7500 Real Time PCR System (Applied Biosystems, Foster City, CA) using Power SYBR Green PCR Master mix (Applied Biosystems) and the thermocycler conditions recommended by the manufacturer. Primers, designed using the computer program Primer Express (Applied Biosystems), were as described in Table 1.

To perform mRNA quantifications, first-strand cDNA was synthesized from $2 \mu \mathrm{g}$ of total RNA using the Superscript first-strand synthesis system for reverse transcriptase (Invitrogen, Carlsbad, CA) with random primers and oligodT according to the manufacturer's directions. Cyclophilin was used to normalize for RNA input amounts and to perform relative quantification. To perform genomic DNA amplification, tyrosine hydroxylase gene was used to normalize for DNA input amounts and to perform relative quantification. Melting curve analysis showed a single sharp peak with the expected $T_{\mathrm{m}}$ for all samples and genes tested. Relative quantities were obtained using the $2^{-\Delta \Delta C t}$ method [27].

\section{Western blot}

Protein extracts were obtained from SCC42B cells at 70\% to $80 \%$ confluence by scraping on ice in lysis buffer containing $50 \mathrm{mmol} / \mathrm{l}$ HEPES (pH 7.9), $250 \mathrm{mmol} / \mathrm{l} \mathrm{NaCl}$, $5 \mathrm{mmol} / \mathrm{l}$ EDTA, 0.2\% NP40, 10\% glycerol, and protease inhibitors $(0.5 \mathrm{mmol} / \mathrm{l}$ phenylmethylsulfonyl fluoride, $1 \mu \mathrm{g} / \mathrm{ml}$ aprotinin, $10 \mu \mathrm{g} / \mathrm{ml}$ leupeptin and $1 \mathrm{mmol} / \mathrm{l} \mathrm{Na}_{3} \mathrm{VO}_{4}$ ). Equal amounts of proteins were fractionated on SDS-PAGE and transferred to PVDF membranes. Membranes were probed with anti-TRPC6 antibody (Abcam) or anti- $\beta$-actin (Sigma-Aldrich) at 1:100 and 1:5000 dilutions, respectively. Bound antibodies were detected using Enhanced Chemiluminescence Reagent (Amersham Pharmacia Biotech) according to the protocol of the manufacturer.

\section{siRNA treatment}

siRNA duplex oligonucleotides (ON-TARGETplus SMARTpool Human TRPC6) were purchased from Dharmacon Research (Lafayette, CO). siCONTROL Nontargeting pool (Dharmacon) were used as control siRNA. SCC42B cells were transfected with $35 \mathrm{pmol} / \mathrm{ml}$ siRNAs using Lipofectamine 2000. TRPC6 mRNA analyses revealed a substantial inhibition (more than $60-70 \%$ ) of TRPC6 expression 48-72 hours after transfection. The transfected cells were used for subsequent experiments within that interval of time.

\section{Wound healing assay}

Cells were grown to confluence in $35-\mathrm{mm}$ tissue culture dishes. Cell monolayers were wounded using a micropipette tip, and floating cells were removed by extensive washing with DMEM. Photographs of the wounded area were taken immediately after making the scratch $(0 \mathrm{~h}$ time point) and after $8 \mathrm{~h}$ using a Leica DMIL microscope to measure the migration rate of cells into the wounded area. At least 15 different fields were randomly chosen across the wound length. For the analysis of the differential cell migration capacity of SCC38, SCC40, and SCC42B cells, the rate of front migration of cell monolayers was analyzed in an AxioObserver.Z1 microscope (Zeiss), equipped with an incubation module, by taking pictures at $0 \mathrm{~h}$ and $8 \mathrm{~h}$ using an EC PlanNeofluor 10x/0.30 Ph1 objective.

\section{Matrigel invasion assays}

In vitro invasion assays were performed by using a 24well invasion chamber coated with Matrigel (Becton Dickinson). Cells were trypsinized, washed with PBS, suspended in DMEM containing 5\% BSA, and plated in the invasion chamber $\left(3 \times 10^{4}\right.$ cells per well). The lower chambers were filled with DMEM containing 5\% BSA with $10 \%$ FBS. After $24 \mathrm{~h}$, the cells remaining in the upper chamber were removed by scraping, whereas the cells that invaded through Matrigel were fixed and stained by using $0.5 \%$ Crystal Violet in methanol. All invading cells were counted by microscopic visualization. All analyses were performed in triplicate.

\section{MTS-based cell proliferation assay}

MTS assays were performed using CellTiter 96 Cell Non-Radioactive Proliferation Assay following the protocol recommended by the manufacturer (Promega, Madison, WI). Briefly, 1000 cells were seeded in each well of 96-well plates, and allowed to growth for 48, 72 or 96 hours. MTS assay was performed at each time point.

\section{Results and discussion}

\section{Array CGH analysis of HNSCC-derived cell lines}

Array CGH was used to characterize genome-wide DNA copy number alterations in five HNSCC-derived cell lines. Visual inspection of the array CGH profiles revealed the presence of an overall pattern that is broadly consistent with the literature in HNSCC (a summary of the chromosomal aberrations is shown in Table 2). Some degree of gain and/or loss was detected in every cell line. The data predicted frequent copy number gains (present 
Table 1 Oligonucleotides used for real time PCR

\begin{tabular}{|c|c|}
\hline Gene & Oligonucleotides \\
\hline \multirow[t]{2}{*}{$J R K L$} & Forward: 5'CGCGATAGTCAGGGAGCTGT 3' \\
\hline & Reverse: 5'GGGTTGGCTGGCAAATAGAC 3' \\
\hline \multirow[t]{2}{*}{ CNTN5 } & Forward: 5'CACCCCATCTCGAATGATCC $3^{\prime}$ \\
\hline & Reverse: 5'GGTGCTGTCTTCGGAACTGC $3^{\prime}$ \\
\hline \multirow[t]{2}{*}{ AD031 } & Forward: 5'TCTCCTGTTGATTCGCAGATGT 3' \\
\hline & Reverse: $5^{\prime}$ TTGAGACCAGTTGATGAATACTCGA $3^{\prime}$ \\
\hline \multirow[t]{2}{*}{$P G R$} & Forward: 5'AACTTCTTGATAACTTGCATGATCTTG $3^{\prime}$ \\
\hline & Reverse: 5'AGCAGTACAGATGAAGTTGTTTGACA 3' \\
\hline \multirow[t]{2}{*}{ TRPC6 } & Forward: 5'TTCTCATGGATGGAGATGCTCA 3' \\
\hline & Reverse: 5'CCATATCATGCCTATTACCCAGGA3' \\
\hline \multirow[t]{2}{*}{ YAP1 } & Forward: 5'GACTTCCTGAACAGTGTGGATGAG 3' \\
\hline & Reverse: 5’TGCTTTGGTTGATAGTATCACCTGTAT $3^{\prime}$ \\
\hline \multirow[t]{2}{*}{ BIRC3 } & Forward: 5'CATCCGTCAAGTTCAAGCCA $3^{\prime}$ \\
\hline & Reverse: 5'GATAGCAGCTGTTCAAGTAGATGAGG 3' \\
\hline \multirow[t]{2}{*}{ PORIMIN } & Forward: 5'TGCTTCATCAGTAACAATCACAACA 3' \\
\hline & Reverse: 5'CCTITCTITGCTTCAGAATGCAT 3' \\
\hline \multirow[t]{2}{*}{ MMP7 } & Forward: 5'CCAGGATGATATTAAAGGCATTCA 3' \\
\hline & Reverse: 5'TGAATTACTTCTCTTTCCATATAGTTTCTGA 3' \\
\hline \multirow[t]{2}{*}{ MMP20 } & Forward: 5'CTGCTCTTCAAGGACCGGATT $3^{\prime}$ \\
\hline & Reverse: 5'TGTCCGCAAGTGAACCTGC 3' \\
\hline \multirow[t]{2}{*}{ MMP27 } & Forward: 5'GCATTTGGTGCTGGAGGTाT 3' \\
\hline & Reverse: 5'ACCCTITGTCCATGGTTTGG 3' \\
\hline \multirow[t]{2}{*}{ MMP8 } & Forward: 5'AGTTGATGCAGTITTCCAGCAA 3' \\
\hline & Reverse: 5'GGTCCACTGAAGACATGGAAGAA 3' \\
\hline \multirow[t]{2}{*}{ MMP10 } & Forward: 5'TGCATCAGGCACCAATTTATTC 3' \\
\hline & Reverse: 5'GAGTGGCCAAGTTCATGAGCA $3^{\prime}$ \\
\hline \multirow[t]{2}{*}{ MMP1 } & Forward: 5'TGGACCAACAATTTCAGAGAGTACA $3^{\prime}$ \\
\hline & Reverse: 5'TTCATGAGCTGCAACACGATG 3' \\
\hline \multirow[t]{2}{*}{ MMP3 } & Forward: 5’TCTITGTAGAGGACAAATACTGGAGATT 3' \\
\hline & Reverse: 5'CCATGGAATTTCTCTTCTCATCAA $3^{\prime}$ \\
\hline \multirow[t]{2}{*}{ MMP12 } & Forward: 5'CGATGAGGACGAATTCTGGAC 3' \\
\hline & Reverse: 5'CAGTGAGGAACAAGTGGTGCC $3^{\prime}$ \\
\hline \multirow[t]{2}{*}{ MMP13 } & Forward: 5'GCCATTACCAGTCTCCGAGG $3^{\prime}$ \\
\hline & Reverse: 5'GCAGGCGCCAGAAGAATCT 3' \\
\hline \multirow[t]{2}{*}{ RNMT } & Forward: 5'GTTCCTGAATTCTTGGTCTATTTCC 3' \\
\hline & Reverse: 5'CTTCTITGCCATTTCATTTAGCAAT 3' \\
\hline \multirow[t]{2}{*}{ MC5R } & Forward: 5'TTGGATCTCAACCTGAATGCC $3^{\prime}$ \\
\hline & Reverse: 5'TTGACATTGGGTCCTGAAAGG 3' \\
\hline \multirow[t]{2}{*}{$M C 2 R$} & Forward: 5'CCTTCTCATTCATTTTGCCCA 3' \\
\hline & Reverse: 5'TCCCAATCACCTTCAGCTCG $3^{\prime}$ \\
\hline \multirow[t]{2}{*}{ ZNF443 } & Forward: 5'GAACCTGGATTGTGTAGTAATGAAATG 3' \\
\hline & Reverse: 5’TGATCTTCAATGTTCTGGTCTTTCC $3^{\prime}$ \\
\hline \multirow[t]{2}{*}{ MAN2B1 } & Forward: 5'GCTCAAAACCGTGGACCAGT 3' \\
\hline & Reverse: 5'GGCGTGCTGGATGTCATTCT 3' \\
\hline
\end{tabular}

Table 1 Oligonucleotides used for real time PCR (Continued)

\begin{tabular}{ll}
\hline JUNB & Forward: 5'AAACTCCTGAAACCGAGCCTG 3' \\
& Reverse: 5'CGCTTGGGACTCCGGTAGG 3' \\
STCH & Forward: 5'AACCCGAGCAATGTCTGGAA 3' \\
& Reverse: 5'TGATTGAAGTCCTGTCCTCCAA 3' \\
NRIP1 & Forward: 5'GGGATCAGGTACTGCCGTTG 3' \\
& Reverse: 5'TCCTCTTCATTATGCCCAGCA 3' \\
CYPA & Forward: 5'CATCTGCACTGCCAGACTGA 3' \\
& Reverse: 5'TTGCCAAACACCACATGCTT 3'
\end{tabular}

in three or more cell lines) for specific segments in 3q, $5 p, 7 p, 8 q, 9 q, 11 q, 14 q, 18 p$, and 20q; and losses for 3p, $9 \mathrm{p}, 11 \mathrm{q}$, and $18 \mathrm{q}$. These copy number alterations, revealed through $\mathrm{CGH}$-array, had been previously detected with conventional metaphase CGH analysis in HNSCC primary samples [1,28]. High-level amplifications were detected at four chromosomal sites including 11q21-q22.2, 18p11.31-p11.21, 19p13.2-p13.13, and 21q11 (see Figure 1). Gains encompassing these genomic regions have been described in previous reports $[11,12,29,30]$. In addition to known regions, our CGH-array analysis disclosed alterations that had never been reported using conventional techniques, such as small gains in 4p12, 13q12, 21q21, and losses in 22q13 (Table 3).

In general, the array CGH data showed that the recurrent genome aberrations described in primary HNSCC tissues are well preserved in the cell lines analyzed here. It also indicates that these cell lines have not accumulated substantial novel recurrent aberrations during extended culture. These data, together with our previous molecular and functional studies [31,32], suggest that analysis of genomic aberrations in the HNSCC-derived cell lines used here might be a useful approach to identify tumor-associated chromosomal regions substantial for the tumorigenesis and progression of HNSCC.

\section{Impact of focal high-level amplifications on gene expression}

To gain some insights into the role of genomic aberrations in HNSCC pathophysiology, we focused in focal amplification events for which it may be easier to pinpoint target genes involved in the pathogenesis of HNSCC.

The present analysis allowed narrowing down and delineating the boundaries of high-level amplification events. Boundaries from the p-telomere span from 95 to $102 \mathrm{Mb}$ (11q21-q22.2), 3,44 to 16,81 Mb (18p11.31p11.21), 11 to13 $\mathrm{Mb}$ (19p13.2-p13.13), and 14,1 to $15,3 \mathrm{Mb}$ (21q11). These are relatively small genomic segments containing 20 or fewer genes (listed in Figure 1) 
Table 2 Most frequently reported chromosomal gains and losses present in HNSCC-derived cell lines

\begin{tabular}{|c|c|c|c|c|c|}
\hline Chro & Region & $\begin{array}{l}\text { Size } \\
(\mathrm{Mb})\end{array}$ & Frequency & Known proto-oncogenes & $\begin{array}{c}\text { Cell line with minimal region of } \\
\text { change }\end{array}$ \\
\hline \multicolumn{6}{|c|}{ Chromosomal gains } \\
\hline $1 \mathrm{p}$ & 1p32.1-p21.1 & 47,25 & $2 / 5$ & - & SCC40 \\
\hline $3 q$ & 3q13.2-qter & 84,9 & $4 / 5$ & $\begin{array}{l}\text { BCL6, EIF4A2, EVI1, GMPS, LPP, MDS1, MLF1, PI3K3CA, RPN1, } \\
\text { TFRC, ZNF9 }\end{array}$ & SCC2 \\
\hline $5 p$ & 5pter-p12 & 45 & $3 / 5$ & LIFR & SCC38 \\
\hline $6 q$ & $6 q 16.3-q 23.3$ & 38,82 & $1 / 5$ & FOXOA3, GOPC, ROS1, STL & SCC40 \\
\hline $7 p$ & 7pter-p14.3 & 32 & $3 / 5$ & ETV1, HOXA9, HOXA11, HOXA13, HNRPA2B1, JAZF1, PMS2 & SCC29 \\
\hline $7 q$ & 7q21.13-q31.1 & 22,87 & $1 / 5$ & AKAP9, CDK6 & SCC2 \\
\hline $8 q$ & $8 q 21.1-q 24.22$ & 64,6 & $5 / 5$ & COX6C, EXT1, MYC, NBS1 & SCC29 \\
\hline $9 p$ & 9p21.2-p13.2 & 12,28 & $2 / 5$ & PAX5, FANCG & SCC29 \\
\hline $9 q$ & $\begin{array}{l}\text { 9q21.33- } \\
\text { q34.11 }\end{array}$ & 43 & $4 / 5$ & FANCC, NR4A3, OMD, PTCH1, SYK, TAL2, XPA & SCC29 \\
\hline \multirow[t]{4}{*}{$11 q$} & $11 q 12.2-q 12.3$ & 1,9 & $4 / 5$ & - & SCC42B \\
\hline & $11 q 13.2-q 22.2$ & 33,1 & $4 / 5$ & PRAD1, NUMA1, PICAM, MAML2, BIRC3 & SCC40 \\
\hline & $11 q 23.3$ & 0,20 & $3 / 5$ & & SCC40 \\
\hline & & & & DDX6 & \\
\hline \multirow[t]{2}{*}{$14 q$} & $14 q 23.1-q 24.2$ & 13,23 & $1 / 5$ & GPHN, RAD51L1 & SCC2 \\
\hline & $14 q 31.1$ & 0,72 & $3 / 5$ & TSHR & SCC2 \\
\hline $18 p$ & $\begin{array}{l}\text { 18p11.31- } \\
\text { p11.21 }\end{array}$ & 13.37 & $4 / 5$ & - & SCC40 \\
\hline $19 p$ & $\begin{array}{l}\text { 19p13.2- } \\
\text { p13.13 }\end{array}$ & 1,64 & $1 / 5$ & LYL1 & SCC42B \\
\hline $20 q$ & $\begin{array}{l}20 \mathrm{q} 11.21- \\
\mathrm{q} 11.23\end{array}$ & 4,86 & $3 / 5$ & - & SCC42B \\
\hline \multicolumn{6}{|c|}{ Chromosomal losses } \\
\hline $1 p$ & 1p13.2-p12 & 7,35 & $2 / 5$ & NRAS, TRIM33 & SCC29, SCC40 \\
\hline $3 p$ & $3 p 23-p 22.3$ & 2,5 & $4 / 5$ & MLH1 & SCC2 \\
\hline $5 q$ & $5 q 11.1-q 12.3$ & 13,11 & $2 / 5$ & - & SCC29, 38 \\
\hline $8 p$ & 8pter-q11.21 & 47,1 & $2 / 5$ & PCM1, FGFR1, WRN, WHSC1L1 & SCC40 \\
\hline $9 p$ & $9 p 21.3$ & 2,61 & $3 / 3$ & CDKN2A, CDKN2B, MLLT3 & SCC29 \\
\hline $10 p$ & 10pter-p11.21 & 37,35 & $2 / 5$ & COPEB, MLLT10, SH3BP1 & SCC2, SCC40 \\
\hline $11 q$ & 11q22.3-qter & 15,29 & $3 / 5$ & $\begin{array}{l}\text { ATM, CBL, DDX10, PAFAH1B2, POU2AF1, SDHD, ZNF145, FLI1, } \\
\text { PRO1073 }\end{array}$ & SCC42B \\
\hline $18 q$ & 18q21.1-qter & 29,97 & $3 / 5$ & BCL2, FVT1, SMAD4, MALT1 & $\operatorname{SCC} 40$ \\
\hline \multirow[t]{2}{*}{$22 q$} & $22 q 11.21$ & 1,03 & $2 / 5$ & BCR, CLTCL1, PNUTL1, SMARCB1 & SCC29 \\
\hline & $22 q 12.1-q 12.2$ & 1,96 & $2 / 5$ & & SCC40 \\
\hline
\end{tabular}

suggesting that any of them may be the target(s) of the amplification. These amplicons do not contain wellestablished oncogenes in HNSCC. To identify putative driver genes in these genomic regions, we compared the expression levels of candidate genes mapping in the amplicons with their DNA copy number status. Figure 1 illustrates genome-wide copy number plots of the gene amplifications and the gene expression data.

Interestingly, a high degree of correlation between DNA and mRNA levels was found for most of the genes selected at 11q, 18p, 19p, and 21q amplicons. This is in agreement with previous studies showing that amplification has a strong impact on transcription levels [33-35]. Expression of RNMT, MC5R, and MC2R genes at 18p11.31-p11.21 amplicon was significantly up-regulated in SCC40 cells that had shown high-level amplification at that locus, compared with cell lines without gene amplification $(\mathrm{p}<0,0001)$ (Figure 1B). Similarly, the expression levels of the STCH and NRIP1 genes at 21q11 were significantly higher in SCC29 cells, which harbored amplification at 

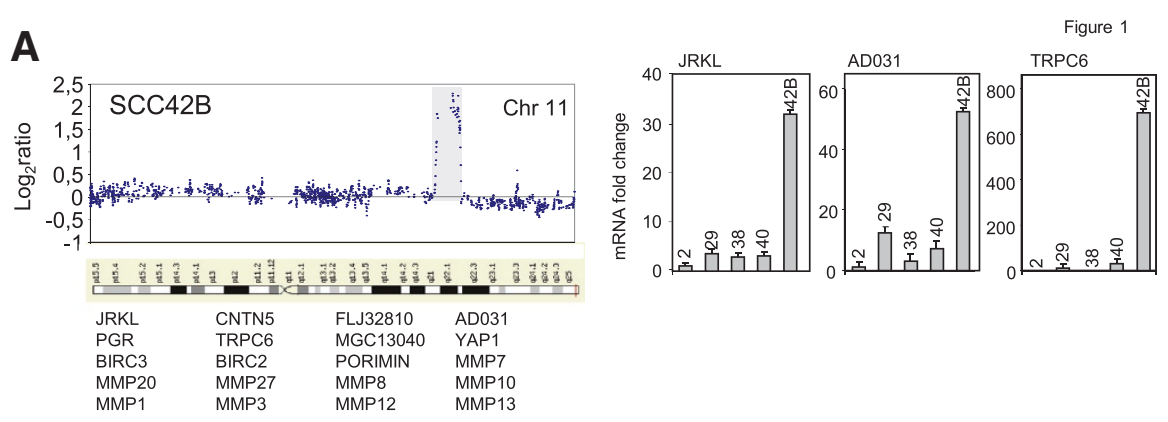

B
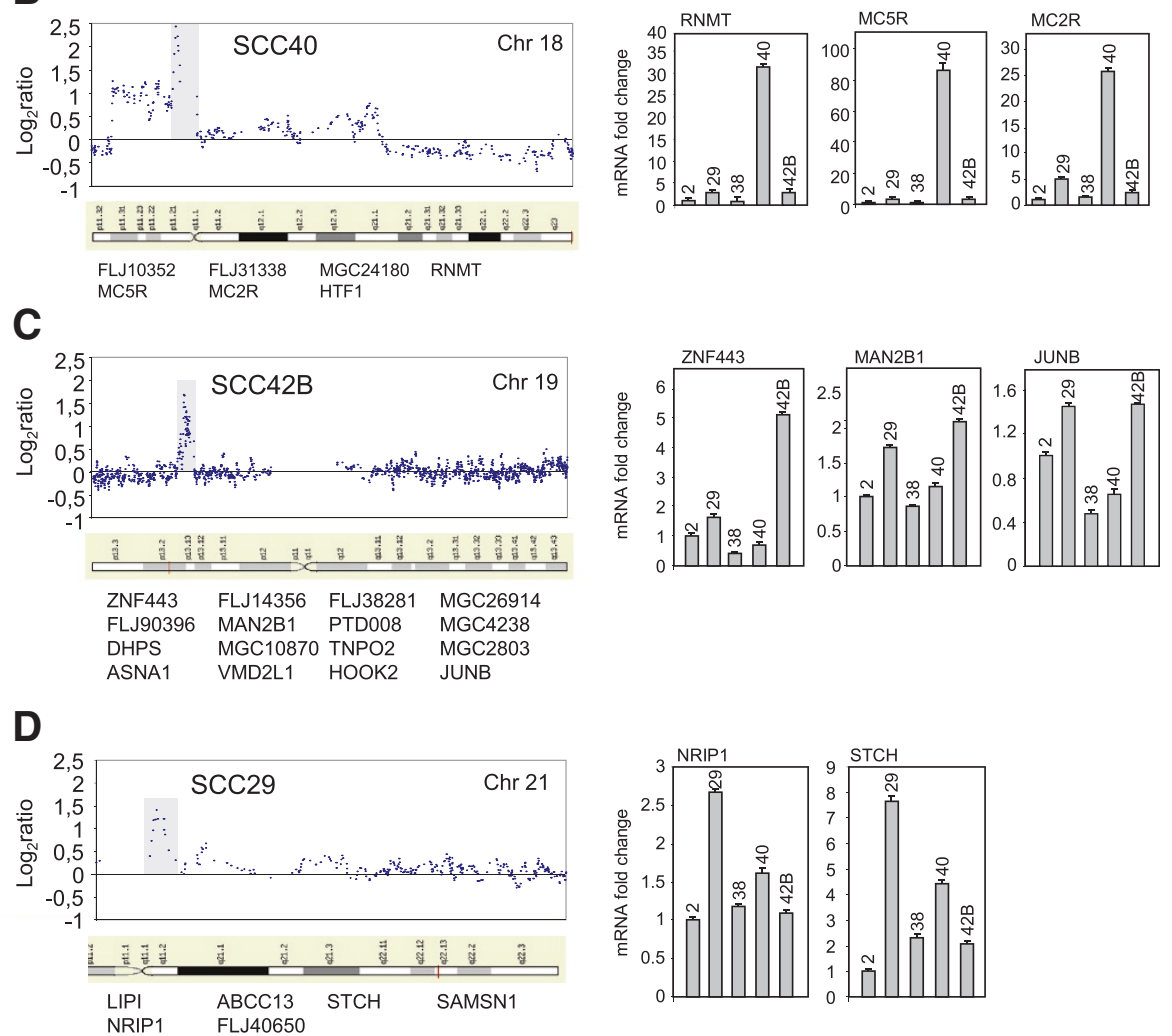

Figure 1 Genome-wide copy number plots of gene amplifications and relative mRNA expression data in HNSCC-derived cell lines. Left panels show the profiles as normalized log2 signal intensity ratios of each spot on the array to the genomic position at chromosome 11 (A), chromosome 18 (B), chromosome 19 (C) from p-to t-telomere, and chromosome 21 (D) from chromosomal band 11 p11.2 to t-telomere. Right panels show the relative mRNA levels of the indicated genes in the HNSCC-derived cell lines. Total RNA was extracted from HNSCC-derived cell lines grown to $80-90 \%$ confluence. mRNA levels were analyzed by RT-qPCR.

Table 3 Non previously identified altered chromosomal regions

\begin{tabular}{lllccll}
\hline Chro & Alteration & Region & Size $(\mathbf{M b})$ & Frequency & Known proto-oncogenes & Cell line with minimal region of change \\
\hline 4 & gain & $4 \mathrm{p} 12$ & 7,08 & $1 / 5$ & $\mathrm{TEC}$ & $\mathrm{SCC} 29$ \\
13 & gain & $13 \mathrm{q} 12.12-\mathrm{q} 12.3$ & 5,49 & $2 / 5$ & $\mathrm{CDX} 2, \mathrm{FLT3}$ & $\mathrm{SCC} 29, \mathrm{SCC} 40$ \\
21 & amplification & $21 \mathrm{q} 11$ & 1,20 & $1 / 5$ & - & $\mathrm{SCC} 29$ \\
& gain & $21 \mathrm{q} 21.1$ & 1,36 & $5 / 5$ & - & $\mathrm{SCC} 29, \mathrm{SCC} 40$ \\
& gain & $21 \mathrm{q} 21.3$ & 4,59 & $2 / 5$ & - & $\mathrm{SCC} 29, \mathrm{SCC} 38$ \\
22 & loss & $22 \mathrm{q} 13.2$ & 0,62 & $5 / 5$ & - & $\mathrm{SCC} 2, \mathrm{SCC} 29$ \\
\hline
\end{tabular}


that locus, than in the other cell lines without gene alteration $(\mathrm{p}<0,01)$ (Figure 1D). Amplification of the ZNF443, and MAN2B1 genes at 19p13.2-p13.13, detected in SCC42B cells, also correlated with higher expression at the mRNA levels as compared with the other cell lines $(\mathrm{p}<0,05)$ (Figure $1 \mathrm{C}$ ). However, quantification of the mRNA levels of the $J U N B$ proto-oncogene (19p13.2-p13.13) revealed that SCC42B cells had similar levels of expression than SCC29 cells, which did not show amplification of the 19p13.2-p13.3 locus. These data indicate that ZNF443 and/or $M A N 2 B 1$ genes, but not $J U N B$, might be candidates of the selection pressure for structural amplification of the 19p13.2-p13.3 region, at least in SCC42B cells. In general, any of the amplified and over-expressed genes identified here (RNMT, MC5R, MC2R, ZNF443, MAN2B1, $N R I P 1$, and $S T C H$ ) might be up-regulated in a DNA copy number-dependent manner and could possibly contribute to HNSCC pathogenesis. To our knowledge, no previous evidence is available on the association of these genes in HNSCC biology. Of all the genes analyzed here, only JUNB has been previously found up-regulated at the mRNA and protein level in HNSCC tumour tissues [36-39]. Our data suggest that its over-expression is caused by mechanisms other than gene amplification. Nevertheless, further studies are required to demonstrate unequivocally whether an association exists between the genetic and expression data in tumour tissue samples.

With regard to the 11q21-q22.2 amplicon, recent studies reported high copy number amplification at this locus in HNSCC $[12,13,30]$. This region contains 18 known genes harbouring two gene clusters, one with nine matrix metalloproteinase $(M M P)$ genes, and other with two baculoviral IAP repeat-containing protein (BIRC) genes. Expression analysis of $B I R C$ and $M M P$ genes in the HNSCCderived cell lines showed no correlation between their mRNA levels and DNA copy number status. In contrast, expression of JRKL, AD031, TRPC6, (Figure 1A), YAP1 and PORIMIN (data not shown) genes were significantly upregulated in SCC42B cells that had shown high-level amplification at that locus, compared with cell lines without gene amplification $(\mathrm{p}<0,01)$. Specifically, mRNA levels of $J R K L$, AD031, TRPC6, YAP1, and PORIMIN were, respectively, $30,50,600,10$, and 8-fold higher in SCC42B cells than in the other cell lines. mRNA expression of other candidate genes at 11q21-q22.2 amplicon (CNTN5, PGR, and $M M P 27)$ was not detected in any of the cell lines. These data exclude CNTN5, PGR, MMP and BIRC genes and point to any of the 5 amplified and over-expressed genes as critical gene-amplification "driver/s". Of them, only TRPC6 and YAP1 genes have been previously found deregulated in several types of cancer. Amplification and mRNA upregulation of $Y A P 1$ has been previously described in several cancers including HNSCC of the oral cavity [20,30,40], sarcomas, meduloblatomas, and mesotheliomas [20,21,41,42].
In addition, recent studies showed that over-expression of YAP1 induces phenotypic alterations that are commonly associated with potent transforming oncogenes [40,42-44]. TRPC6 is a member of the TRP family of $\mathrm{Ca}^{2+}$ - and $\mathrm{Na}^{+}$-permeable channels shown to be up-regulated in glioblastomas and breast, prostate, gastric, and oesophageal cancer cells [23,45-48]. Our data revealed that this was the most dramatically up-regulated gene in SCC42B cells. However, to the best of our knowledge, up-regulation of TRPC6 has not been previously identified in HNSCC.

\section{TRPC6 gene is amplified and over-expressed in HNSCC-} tissue specimens

TRPC6 DNA and mRNA levels were analyzed in a panel of 24 primary tumors (Table 4). Eight out of 24 tumor samples displayed increased gene copy number as compared with a pool of DNA samples obtained from normal mucosa of five healthy individuals. Analysis of TRPC6 mRNA levels revealed that it was absent in normal mucosa from noncancer patients. Similarly, it was either absent or barely

Table 4 Relative TRPC6 DNA and mRNA levels in HNSCC primary tumors

\begin{tabular}{|c|c|c|}
\hline Tumor sample & Genomic TRPC6 DNA levels* & TRPC6 mRNA Levels" \\
\hline $7 \mathrm{~T}$ & 5.70 & 1.7 \\
\hline $8 T$ & 0.67 & 1.2 \\
\hline $11 \mathrm{~T}$ & 2.01 & 2,85 \\
\hline $12 \mathrm{~T}$ & 1.60 & 1.38 \\
\hline $13 \mathrm{~T}$ & 3.90 & 1.9 \\
\hline $14 \mathrm{~T}$ & 0.60 & 0.56 \\
\hline $17 \mathrm{~T}$ & 2.00 & 1.01 \\
\hline $21 \mathrm{~T}$ & 3.00 & 5.77 \\
\hline $23 \mathrm{~T}$ & 1.27 & 7.5 \\
\hline $25 \mathrm{~T}$ & 1.27 & 1.05 \\
\hline $26 \mathrm{~T}$ & 1.75 & 5.91 \\
\hline $27 \mathrm{~T}$ & 1.55 & 1.84 \\
\hline $32 \mathrm{~T}$ & 2.60 & 1.7 \\
\hline $33 \mathrm{~T}$ & 1.40 & 9.53 \\
\hline $95 \mathrm{~T}$ & 0.37 & 1.46 \\
\hline $110 \mathrm{~T}$ & 1.60 & 1.38 \\
\hline $112 \mathrm{~T}$ & 2.90 & 4.14 \\
\hline $124 \mathrm{~T}$ & 0.80 & 2.87 \\
\hline $127 \mathrm{~T}$ & 0.86 & 1.76 \\
\hline $141 \mathrm{~T}$ & 3.59 & 19.02 \\
\hline $143 \mathrm{~T}$ & 0.60 & 1.03 \\
\hline $147 \mathrm{~T}$ & 0.60 & 0.16 \\
\hline $154 \mathrm{~T}$ & 1.40 & 0.41 \\
\hline $155 \mathrm{~T}$ & 0.61 & 0.16 \\
\hline
\end{tabular}

"Values showing gene gain (\#2) and increased mRNA levels (\#1.7) are indicated in bold. 
detectable in all clinically normal mucosa adjacent to tumors, and in 11/24 tumor samples. In contrast, 13 tumor tissues displayed TRPC6 mRNA levels that were 1.7- to 19-fold above the highest level found in normal mucosa. All but one tumor showing increased TRPC6 gene dosage also harbored TRPC6 mRNA over-expression. These data suggest that TRPC6 amplification may be responsible for TRPC6 over-expression and is a candidate driver gene in 11q21-q22.2 amplicon that may play a role in HNSCC pathophysiology.

\section{Inhibition of TRPC6 expression does not induce changes in SCC42B cell proliferation}

Previous studies have shown that inhibition of TRPC6 expression results in decreased cell proliferation in cancer cells $[23,24,47,49,50]$. To investigate the possible role of TRPC6 on cell proliferation of HNSCC cells, MTS assays and cell counting were performed in SCC42B cells expressing siRNA against TRPC6, and in their corresponding control cells. As shown in Figure 2, inhibition of TRPC6 expression did not affect significantly the cell growth rates. Accordingly, the number of cells in each phase of the cell cycle was similar in SCC42B cells transfected with TRPC6 siRNA versus control siRNA (data not shown). We did not find association between the proliferation rate of SCC cells and the presence of TRPC6 gene amplification and overexpression. SCC42B cells carrying 11q21-q22.2 amplification proliferate more rapidly than SCC29 and SCC40 cells, but they growth at similar rates than SCC38 and SCC2 cells (data not shown). These data show that, in the tumour background examined here, TRPC6 is not important for cell proliferation.

\section{Inhibition of TRPC6 expression impairs cell migration and invasion}

In addition to cell proliferation, $\mathrm{Ca}^{2+}$ signaling is known to be involved in cell locomotion. It was therefore tempting to speculate that SCC42B cells have a high migratory capacity. Comparison of the cell migration behavior of SCC38, SCC40 and SCC42B cells revealed that the migratory potential of SCC42B cells, which express high levels of TRPC6 and harbor 11q21-q22.2 amplification, was significantly higher than that of SCC38 and SCC40 cells, containing lower levels of TRPC6 mRNA and genomic DNA (Figure 3A and B). This different phenotype may be the result of different levels of TRPC6 gene expression or, alternatively, could be caused by other gene(s)/protein(s) structural or functional alterations in the cell lines

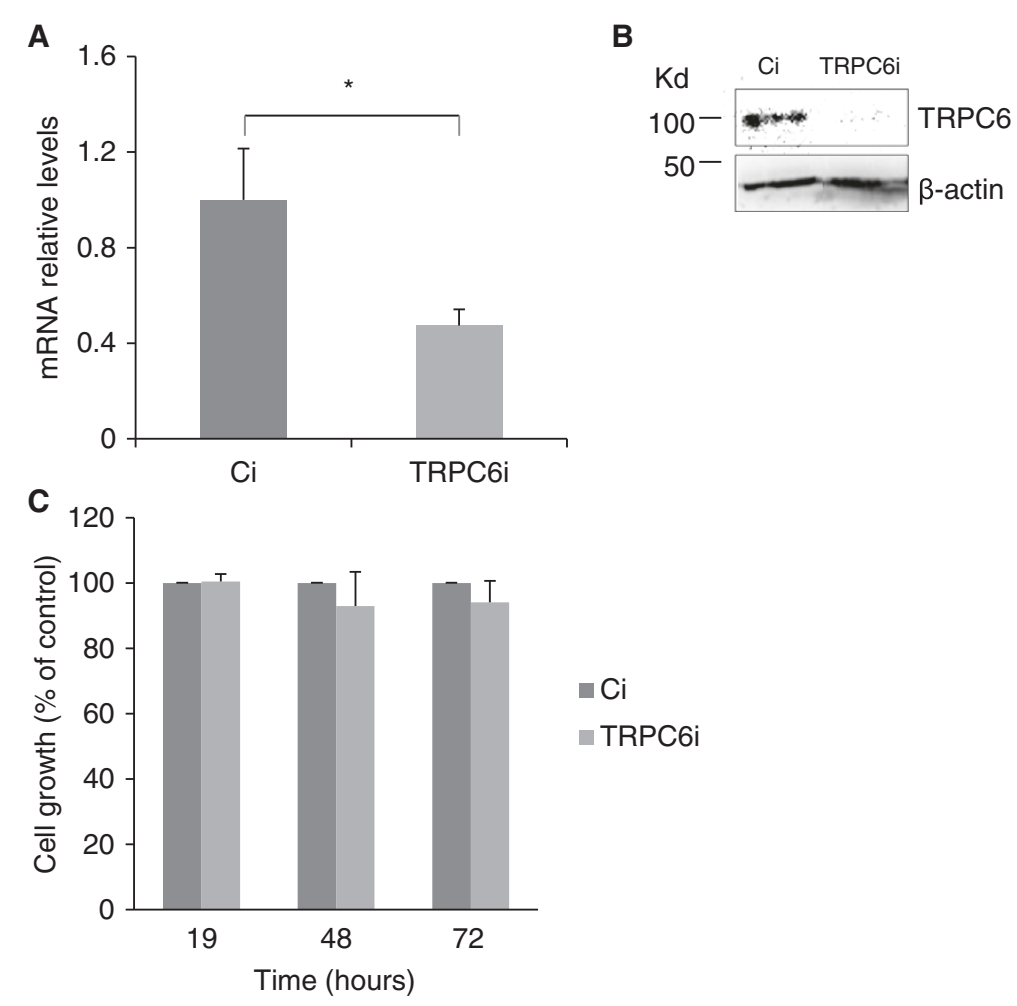

Figure 2 TRPC6 inhibition does not affect cell proliferation in SCC42B cells. SCC42B cells were transfected with control (Ci) or TRPC6-siRNA (TRPC6i) 48 hours before MTS assay. (A and B) Reduction of TRPC6 mRNA (A) and protein (B) levels by siRNA treatment. Transcripts were quantified using RT-qPCR. The mean of relative expression to cyclophilin A housekeeping gene of at least three independent experiments is shown. (C) Cell growth was determined using a colorimetric MTS assay. Columns, mean cell growth relative to control of three independent experiments. ${ }^{*} p<0.05$ paired Student's $t$ test. 
explored here. We therefore sought to determine whether inhibition of TRPC6 expression by siRNAs affects cell migration in SCC42B cells. As shown in Figure 3D, knock down of TRPC6 expression by siRNA resulted in a $36 \%$ decrease in cell migration as compared with cells transfected with nonspecific siRNAs. SCC42B cells were also analyzed for their invasive potential through a B1-mm Matrigel barrier compared with cells transfected with TRPC6 siRNA. The data revealed that invasion was dramatically inhibited with TRPC6 siRNA expression showing a 90\% decrease in invasiveness (Figure $3 \mathrm{C}$ and $\mathrm{E}$ ).

Plasma membrane ion channels contribute to virtually all basic cellular processes and are also involved in the malignant phenotype of cancer cells by modulating different hallmarks of cancer such as proliferation, cellular locomotion, and tissue invasion. Specifically, the morphological and adherence changes of metastatic cells involve $\mathrm{Ca}^{2+}$ signaling supported by enhanced $\mathrm{Ca}^{2+}$ influx. Recently, TRPC6 has emerged as an important player in the control of the aggressive phenotype of glioblastoma cells [23]. Our analysis of the functional significance of TRPC6 overexpression in HNSCC showed that TRPC6 also modulates cell invasion in HNSCC cells. This finding is of interest as it provides the opportunity to therapeutically target TRPC6 to interfere with $\mathrm{Ca}^{2+}$-dependent signaling involved in cell invasion.

\section{Conclusions}

In the present study, we report that TRPC6 (11q22) is overexpressed in HNSCC, and provide new evidence that increase in gene dosage is a novel mechanism to activate TRPC6 expression in cancer. Increased TRPC6 mRNA and gene dosage was detected in both, cell lines and tumor tissues, revealing that this molecular alteration can be pathologically relevant in HNSCC. In addition, siRNA-induced knockdown of TRPC6 expression in HNSCC-derived cells dramatically inhibited HNSCC-cell invasion. Therefore, TRPC6 is likely to be a target for amplification that confers enhanced invasive behavior to HNSCC cells and, therefore, may be a promising therapeutic target in the treatment of HNSCC. These data provide the foundation for further
A

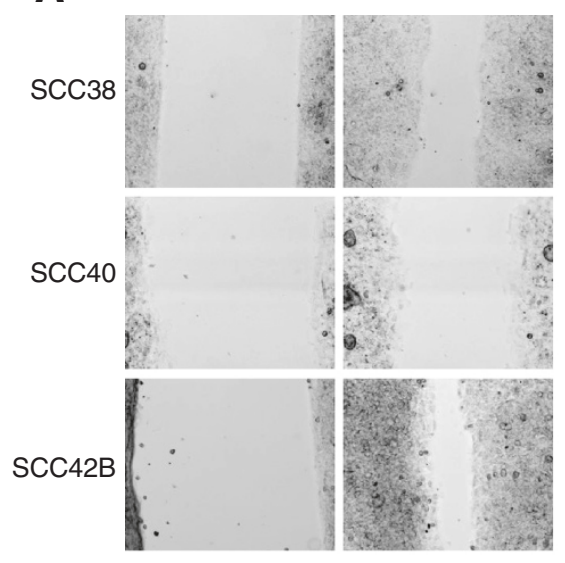

D

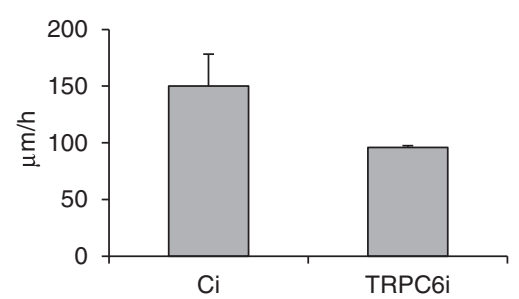

B

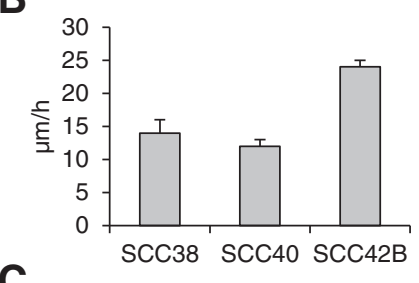

C

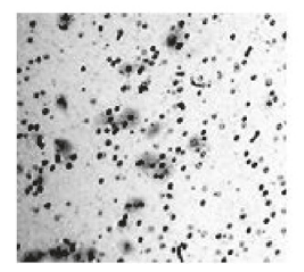

Ctrli

E

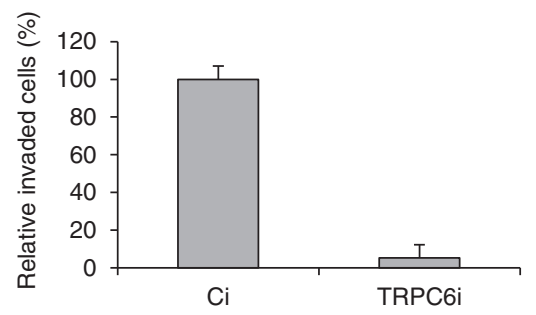

Figure 3 Inhibition of TRPC6 gene expression decreases cellular migration and invasion. (A and B) Wound healing assays were performed in SCC38, SCC40 and SCC42B cells. The rate of front migration of cell monolayers was analyzed by time-lapse video microscopy. At least 15 different fields were randomly chosen across the wound length. Values are mean of average \pm s.d. from three independent experiments. (C and E) SCC42B cells treated with control (Ci) or TRPC6 siRNA (TRPC6i) were seeded in serum-free media in the upper chamber of Matrigel transwells. The lower chamber was loaded with regular media supplemented with $10 \%$ fetal bovine serum and $5 \% \mathrm{BSA}$. After $24 \mathrm{~h}$ at $37^{\circ} \mathrm{C}$ in $5 \% \mathrm{CO}_{2}$, the top filter was scraped, and invading cells were fixed and stained. (C) Representative images captured with a 10 objective $24 \mathrm{~h}$ after seeding. (E) All invading cells were counted under $\times 10$ magnification. Values are mean of average \pm s.d. from three independent experiments done in triplicate. (D) Inhibition of TRPC6 expression in SCC42B cells attenuates cell migration. Wound healing assays were performed in cells treated with TRPC6- (TRPC6i) or control-siRNA (Ci). Values are mean of average \pm s.d. from three independent experiments. 
functional validation of this putative candidate gene in tumor tissues to determine whether it is crucial for tumor development or progression.

\section{Competing interests}

The authors declare that they have no competing interests.

\section{Authors' contributions}

SBQ and AM carried out the functional assays and the molecular genetic studies. PS and IZ carried out the gene expression studies. ISS and ND participated in the invasion assays. CS, EJ and RS participated in the acquisition of the data and performed the statistical analysis. MDC conceived of the study, participated in its design and coordination, and drafted the manuscript. All authors read and approved the final manuscript.

\section{Acknowledgements}

This work was supported by Instituto de Salud Carlos III-Fondo de Investigación Sanitaria [FIS PI11/929 to M.-D.C and C.S.]; Red Temática de Investigación Cooperativa en Cáncer [RD12/0036/0015] Instituto de Salud Carlos III (ISCIII), Spanish Ministry of Economy and Competitiveness \& European Regional Development Fund (ERDF); and Obra Social CajAstur-Instituto Universitario de Oncología del Principado de Asturias.

\section{Author details}

${ }^{1}$ Servicio de Otorrinolaringología, Hospital Universitario Central de Asturias, Instituto Universitario de Oncología del Principado de Asturias, Universidad de Oviedo, Oviedo, Spain. 'Laboratorio Oncología Molecular, Fundación para la Investigación del Hospital General Universitario de Valencia, Valencia, Spain. ${ }^{3}$ Departamento de Biotecnología, Universidad Politécnica de Valencia, Valencia, Spain.

\section{Received: 5 October 2012 Accepted: 7 March 2013}

Published: 14 March 2013

\section{References}

1. Akervall J: Genomic screening of head and neck cancer and its implications for therapy planning. Eur Arch Otorhinolaryngol 2006, 263:297-304.

2. Squire JA, Bayani J, Luk C, Unwin L, Tokunaga J, MacMillan C, Irish J, Brown D, Gullane P, Kamel-Reid S: Molecular cytogenetic analysis of head and neck squamous cell carcinoma: by comparative genomic hybridization, spectral karyotyping, and expression array analysis. Head Neck 2002, 24:874-887.

3. Perez-Ordonez B, Beauchemin M, Jordan RC: Molecular biology of squamous cell carcinoma of the head and neck. J Clin Pathol 2006, 59:445-453

4. Tan KD, Zhu Y, Tan HK, Rajasegaran V, Aggarwal A, Wu J, Wu HY, Hwang J, Lim DT, Soo KC, Tan P: Amplification and overexpression of PPFIA1, a putative 11q13 invasion suppressor gene, in head and neck squamous cell carcinoma. Genes Chromosomes Cancer 2008, 47:353-362.

5. Rodrigo JP, Garcia LA, Ramos S, Lazo PS, Suarez C: EMS1 Gene amplification correlates with poor prognosis in squamous cell carcinomas of the head and neck. Clin Cancer Res 2000, 6:3177-3182.

6. Callender T, el-Naggar AK, Lee MS, Frankenthaler R, Luna MA, Batsakis JG: PRAD-1 (CCND1)/cyclin D1 oncogene amplification in primary head and neck squamous cell carcinoma. Cancer 1994, 74:152-158.

7. Huang X, Gollin SM, Raja S, Godfrey TE: High-resolution mapping of the $11 q 13$ amplicon and identification of a gene, TAOS1, that is amplified and overexpressed in oral cancer cells. Proc Natl Acad Sci U S A 2002, 99:11369-11374.

8. Gorogh T, Weise JB, Holtmeier C, Rudolph P, Hedderich J, Gottschlich S, Hoffmann M, Ambrosch P, Csiszar K: Selective upregulation and amplification of the lysyl oxidase like-4 (LOXL4) gene in head and neck squamous cell carcinoma. J Pathol 2007, 212:74-82.

9. Begum A, Imoto I, Kozaki K, Tsuda H, Suzuki E, Amagasa T, Inazawa J: Identification of PAK4 as a putative target gene for amplification within 19q13.12-q13.2 In oral squamous-cell carcinoma. Cancer Sci 2009. 100:1908-1916.

10. Secades P, Rodrigo JP, Hermsen M, Alvarez C, Suarez C, Chiara MD: Increase in gene dosage is a mechanism of HIF-1alpha constitutive expression in head and neck squamous cell carcinomas. Genes Chromosomes Cancer 2009, 48:441-454.

11. Singh B, Gogineni SK, Sacks PG, Shaha AR, Shah JP, Stoffel A, Rao PH: Molecular cytogenetic characterization of head and neck squamous cell carcinoma and refinement of 3q amplification. Cancer Res 2001, 61:4506-4513

12. Baldwin C, Garnis C, Zhang L, Rosin MP, Lam WL: Multiple microalterations detected at high frequency in oral cancer. Cancer Res 2005, 65:7561-7567.

13. Roman E, Meza-Zepeda LA, Kresse SH, Myklebost O, Vasstrand EN, Ibrahim SO: Chromosomal aberrations in head and neck squamous cell carcinomas in Norwegian and Sudanese populations by array comparative genomic hybridization. Oncol Rep 2008, 20:825-843.

14. Weber RG, Sommer C, Albert FK, Kiessling M, Cremer T: Clinically distinct subgroups of glioblastoma multiforme studied by comparative genomic hybridization. Lab Invest 1996, 74:108-119.

15. Knuutila S, Bjorkqvist AM, Autio K, Tarkkanen M, Wolf M, Monni O, Szymanska J, Larramendy ML, Tapper J, Pere H, et al: DNA copy number amplifications in human neoplasms: review of comparative genomic hybridization studies. Am J Pathol 1998, 152:1107-1123.

16. Menghi-Sartorio S, Mandahl N, Mertens F, Picci P, Knuutila S: DNA copy number amplifications in sarcomas with homogeneously staining regions and double minutes. Cytometry 2001, 46:79-84.

17. Imoto I, Tsuda H, Hirasawa A, Miura M, Sakamoto M, Hirohashi S, Inazawa J: Expression of CIAP1, a target for 11q22 amplification, correlates with resistance of cervical cancers to radiotherapy. Cancer Res 2002. 62:4860-4866

18. Dai Z, Zhu WG, Morrison CD, Brena RM, Smiraglia DJ, Raval A, Wu YZ, Rush $L$, Ross P, Molina JR, et al: A comprehensive search for DNA amplification in lung cancer identifies inhibitors of apoptosis CIAP1 and CIAP2 as candidate oncogenes. Hum Mol Genet 2003, 12:791-801.

19. Bashyam MD, Bair R, Kim YH, Wang P, Hernandez-Boussard T, Karikari CA Tibshirani R, Maitra A, Pollack JR: Array-based comparative genomic hybridization identifies localized DNA amplifications and homozygous deletions in pancreatic cancer. Neoplasia 2005, 7:556-562.

20. Helias-Rodzewicz Z, Perot G, Chibon F, Ferreira C, Lagarde P, Terrier P, Coindre JM, Aurias A: YAP1 And VGLL3, encoding two cofactors of TEAD transcription factors, are amplified and overexpressed in a subset of soft tissue sarcomas. Genes Chromosomes Cancer 2010, 49:1161-1171.

21. Fernandez LA, Northcott PA, Dalton J, Fraga C, Ellison D, Angers S, Taylor $M D$, Kenney AM: YAP1 Is amplified and up-regulated in hedgehogassociated medulloblastomas and mediates sonic hedgehog-driven neural precursor proliferation. Genes Dev 2009, 23:2729-2741.

22. Muramatsu T, Imoto I, Matsui T, Kozaki K, Haruki S, Sudol M, Shimada Y, Tsuda H, Kawano T, Inazawa J: YAP is a candidate oncogene for esophageal squamous cell carcinoma. Carcinogenesis 2010, 32:389-398.

23. Chigurupati S, Venkataraman R, Barrera D, Naganathan A, Madan M, Paul L, Pattisapu JV, Kyriazis GA, Sugaya K, Bushnev S, et al: Receptor channel TRPC6 is a key mediator of notch-driven glioblastoma growth and invasiveness. Cancer Res 2010, 70:418-427.

24. Ding X, He Z, Zhou K, Cheng J, Yao H, Lu D, Cai R, Jin Y, Dong B, Xu Y, Wang Y: Essential role of TRPC6 channels in G2/M phase transition and development of human glioma. J Natl Cancer Inst 2010, 102:1052-1068.

25. Lansford CDGR, Bier H, et al: Head and neck cancers. Dordrecht: Kluwer Academic Press; 1999.

26. van den ljssel P, Tijssen M, Chin SF, Eijk P, Carvalho B, Hopmans E, Holstege $H$, Bangarusamy DK, Jonkers J, Meijer GA, et al: Human and mouse oligonucleotide-based array CGH. Nucleic Acids Res 2005, 33:e192.

27. Livak KJ, Schmittgen TD: Analysis of relative gene expression data using real-time quantitative $P C R$ and the 2(-delta delta $C(T))$ method. Methods 2001, 25:402-408.

28. Gollin SM: Chromosomal alterations in squamous cell carcinomas of the head and neck: window to the biology of disease. Head Neck 2001, 23:238-253.

29. Smeets SJ, Braakhuis BJ, Abbas S, Snijders PJ, Ylstra B, van de Wiel MA, Meijer GA, Leemans CR, Brakenhoff RH: Genome-wide DNA copy number alterations in head and neck squamous cell carcinomas with or without oncogene-expressing human papillomavirus. Oncogene 2006, $25: 2558-2564$

30. Snijders AM, Schmidt BL, Fridlyand J, Dekker N, Pinkel D, Jordan RC, Albertson DG: Rare amplicons implicate frequent deregulation of cell fate 
specification pathways in oral squamous cell carcinoma. Oncogene 2005, 24:4232-4242

31. Canel M, Secades P, Garzon-Arango M, Allonca E, Suarez C, Serrels A, Frame $M$, Brunton V, Chiara MD: Involvement of focal adhesion kinase in cellular invasion of head and neck squamous cell carcinomas via regulation of MMP-2 expression. Br J Cancer 2008, 98:1274-1284.

32. Canel M, Secades P, Rodrigo JP, Cabanillas R, Herrero A, Suarez C, Chiara MD: Overexpression of focal adhesion kinase in head and neck squamous cell carcinoma is independent of fak gene copy number. Clin Cancer Res 2006, 12:3272-3279.

33. Neve RM, Chin K, Fridlyand J, Yeh J, Baehner FL, Fevr T, Clark L, Bayani N, Coppe JP, Tong F, et al: A collection of breast cancer cell lines for the study of functionally distinct cancer subtypes. Cancer Cell 2006, 10:515-527.

34. Jarvinen AK, Autio R, Kilpinen S, Saarela M, Leivo I, Grenman R, Makitie AA, Monni O: High-resolution copy number and gene expression microarray analyses of head and neck squamous cell carcinoma cell lines of tongue and larynx. Genes Chromosomes Cancer 2008, 47:500-509.

35. Lockwood WW, Chari R, Coe BP, Girard L, Macaulay C, Lam S, Gazdar AF, Minna JD, Lam WL: DNA amplification is a ubiquitous mechanism of oncogene activation in lung and other cancers. Oncogene 2008, 27:4615-4624

36. Weber A, Hengge UR, Stricker I, Tischoff I, Markwart A, Anhalt K, Dietz A, Wittekind C, Tannapfel A: Protein microarrays for the detection of biomarkers in head and neck squamous cell carcinomas. Hum Pathol 2007, 38:228-238.

37. Pacheco MM, Kowalski LP, Nishimoto IN, Brentani MM: Differential expression of $c$-jun and $c$-fos mRNAs in squamous cell carcinoma of the head and neck: associations with UPA, gelatinase $B$, and matrilysin mRNAs. Head Neck 2002, 24:24-32.

38. Xie M, Sun Y, Li Y: Expression of matrix metalloproteinases in supraglottic carcinoma and its clinical implication for estimating lymph node metastases. Laryngoscope 2004, 114:2243-2248.

39. Werner JA, Rathcke IO, Mandic R: The role of matrix metalloproteinases in squamous cell carcinomas of the head and neck. Clin Exp Metastasis 2002, 19:275-282.

40. Zhang L, Ye DX, Pan HY, Wei K, Wang LZ, Wang XD, Shen GF, Zhang ZY: Yes-associated protein promotes cell proliferation by activating Fos related activator-1 in oral squamous cell carcinoma. Oral Oncol 2011, 47:693-697.

41. Yokoyama T, Osada H, Murakami H, Tatematsu Y, Taniguchi T, Kondo Y, Yatabe $Y$, Hasegawa $Y$, Shimokata K, Horio Y, et al: YAP1 Is involved in mesothelioma development and negatively regulated by Merlin through phosphorylation. Carcinogenesis 2008, 29:2139-2146.

42. Diep CH, Zucker KM, Hostetter G, Watanabe A, Hu C, Munoz RM, Von Hoff $\mathrm{DD}$, Han H: Down-regulation of Yes associated protein 1 expression reduces cell proliferation and clonogenicity of pancreatic cancer cells. PLoS One, 7:e32783.

43. Kang W, Tong JH, Chan AW, Lee TL, Lung RW, Leung PP, So KK, Wu K, Fan $D, Y u J$, et al: Yes-associated protein 1 exhibits oncogenic property in gastric cancer and its nuclear accumulation associates with poor prognosis. Clin Cancer Res 2011, 17:2130-2139.

44. Overholtzer M, Zhang J, Smolen GA, Muir B, Li W, Sgroi DC, Deng CX, Brugge JS, Haber DA: Transforming properties of YAP, a candidate oncogene on the chromosome 11 q22 amplicon. Proc Natl Acad Sci U S A 2006, 103:12405-12410.

45. Guilbert A, Dhennin-Duthille I, Hiani YE, Haren N, Khorsi H, Sevestre H, Ahidouch A, Ouadid-Ahidouch H: Expression of TRPC6 channels in human epithelial breast cancer cells. BMC Cancer 2008, 8:125.

46. Yue $D$, Wang $Y$, Xiao JY, Wang P, Ren CS: Expression of TRPC6 in benign and malignant human prostate tissues. Asian J Androl 2009, 11:541-547.

47. Cai R, Ding X, Zhou K, Shi Y, Ge R, Ren G, Jin Y, Wang Y: Blockade of TRPC6 channels induced G2/M phase arrest and suppressed growth in human gastric cancer cells. Int J Cancer 2009, 125:2281-2287.

48. Shi Y, Ding X, He ZH, Zhou KC, Wang Q, Wang YZ: Critical role of TRPC6 channels in $\mathrm{G} 2$ phase transition and the development of human oesophageal cancer. Gut 2009, 58:1443-1450.
49. Thebault $S$, Flourakis $M$, Vanoverberghe $K$, Vandermoere F, Roudbaraki $M$ Lehen'kyi V, Slomianny C, Beck B, Mariot P, Bonnal JL, et al: Differential role of transient receptor potential channels in Ca2+ entry and proliferation of prostate cancer epithelial cells. Cancer Res 2006 66:2038-2047

50. El Boustany C, Bidaux G, Enfissi A, Delcourt P, Prevarskaya N, Capiod T: Capacitative calcium entry and transient receptor potential canonical 6 expression control human hepatoma cell proliferation. Hepatology 2008 47:2068-2077.

doi:10.1186/1471-2407-13-116

Cite this article as: Bernaldo de Quirós et al: Identification of TRPC6 as a possible candidate target gene within an amplicon at 11q21-q22.2 for migratory capacity in head and neck squamous cell carcinomas. BMC Cancer 2013 13:116.

\section{Submit your next manuscript to BioMed Central and take full advantage of:}

- Convenient online submission

- Thorough peer review

- No space constraints or color figure charges

- Immediate publication on acceptance

- Inclusion in PubMed, CAS, Scopus and Google Scholar

- Research which is freely available for redistribution

Submit your manuscript at www.biomedcentral.com/submit
C Biomed Central 